\title{
An Empirical Formula of Mean Specific Heat Capacity of Ideal Gases
}

\author{
XIAO Hong ${ }^{1,}$, , LIU Hui ${ }^{2, b^{*}}$ \\ ${ }^{1}$ School of Computer Science, Xi'an Shiyou University, Xi'an, P.R. China, 710065 \\ ${ }^{2}$ School of Mechanical Engineering, Xi'an Shiyou University, Xi'an, P.R. China, 710065 \\ a xiaohong@xsyu.edu.cn, ${ }^{\mathrm{b}}$ xibeiliu@163.com
}

Keywords: Thermodynamics; Ideal gas; Mean specific heat capacity; Formula; Fitting

\begin{abstract}
The method of formulation of tabular data of mean specific heat capacity of gases is discussed and an empirical formula to fit these data is given in this paper. A linear function of temperature is chosen as the formula to piecewise fit mean isobaric specific heat capacity data over a wide range of temperature. For seven gases including air, $\mathrm{CO}, \mathrm{CO}_{2}, \mathrm{O}_{2}, \mathrm{~N}_{2}, \mathrm{H}_{2} \mathrm{O}$ and $\mathrm{SO}_{2}$, the coefficients of the formula are regressed by means of least square method in the range of temperature $0{ }^{\circ} \mathrm{C}$ to $1200^{\circ} \mathrm{C}$ and listed. The whole temperature interval is divided into 3 subintervals: $0-300^{\circ} \mathrm{C}, 300$ - $800^{\circ} \mathrm{C}$ and $800-1200^{\circ} \mathrm{C}$, and fitting is done in the subintervals. The average deviations of the calculated values of the formula and reference values of mean isobaric specific heat capacity are less than $0.3 \%$ for all the gases in the temperature range from 0 to $1200^{\circ} \mathrm{C}$, except $\mathrm{CO}_{2}$. For $\mathrm{CO}_{2}$, only in the subinterval of $300{ }^{\circ} \mathrm{C}$ to $800{ }^{\circ} \mathrm{C}$ is the average deviation $0.36 \%$, and in other subintervals the average deviations are less than $0.3 \%$.
\end{abstract}

\section{Introduction}

Calculation of enthalpy difference and thermodynamic energy difference is essential in the analysis and calculation of thermodynamic engineering. For ideal gases, enthalpy and thermodynamic energy are a function only of temperature, and then enthalpy difference and thermodynamic energy difference at two states are calculated as follows $[1,2]$

$$
\begin{aligned}
& \Delta h=\int_{1}^{2} c_{p} d T . \\
& \Delta u=\int_{1}^{2} c_{v} d T .
\end{aligned}
$$

Where $h$ is enthalpy $(\mathrm{kJ} / \mathrm{kg}), u$ is thermodynamic energy $(\mathrm{kJ} / \mathrm{kg}), c_{\mathrm{p}}$ is ideal gas isobaric specific heat capacity $\left(\mathrm{kJ} / \mathrm{kg}{ }^{\circ} \mathrm{C}\right), c_{\mathrm{v}}$ is ideal gas isochoric specific heat capacity $\left(\mathrm{kJ} / \mathrm{kg}{ }^{\circ} \mathrm{C}\right)$, and $T$ is temperature $(\mathrm{K})$

Although ideal gases do not exist in nature, the thermodynamic calculation based on ideal gases is basic for thermodynamic calculation for real gases. For gases at normal pressure or a little higher pressure, real gases can be treated as ideal gases. Eq.11 and Eq.12 are widely applied in thermal engineering for both ideal gases and real gases [3, 4, 5].

For ideal gases, specific heat capacity either at constant pressure or at constant volume is only a function of temperature. Equations of different forms $[6,7]$ are used to represent the relationship between specific heat capacity and temperature, with a polynomial being common. A cubic polynomial is often used to express the relation between gas specific heat and temperature

$$
c_{p}=c_{0}+c_{1} T+c_{2} T^{2}+c_{3} T^{3}
$$


The coefficients of Eq. (3) are referred in many books [6, 7]. Therefore

$$
\Delta h=\int_{1}^{2} c_{p} d T=c_{0} T_{2}+c_{1} T_{2}^{2} / 2+c_{2} T_{2}^{3} / 3+c_{3} T_{2}^{4} / 4-c_{0} T_{1}-c_{1} T_{1}^{2} / 2-c_{2} T_{1}^{3} / 3-c_{3} T_{1}^{4} / 4
$$

If accurate calculation is not required, the value of specific heat capacities can be treated as a constant in the calculation of enthalpy difference and thermodynamic energy difference. If accurate calculation is necessary, the integration of Equation (1) and (2) is needed and the process of calculation, like Eq.(4), is relatively inconvenient. For convenience and accuracy, the concept of mean specific heat capacity $[1,7]$ is introduced in engineering analysis to simplify the calculation process. Note

$$
\begin{aligned}
& \Delta h=\int_{t_{1}}^{t_{2}} c_{p} d t=\int_{0}^{t_{2}} c_{p} d t-\int_{0}^{t_{1}} c_{p} d t . \\
& \Delta u=\int_{t_{1}}^{t_{2}} c_{v} d t=\int_{0}^{t_{2}} c_{v} d t-\int_{0}^{t_{1}} c_{v} d t .
\end{aligned}
$$

Mean specific heat capacity at constant pressure and mean specific heat capacity at constant volume in the temperature range of $0 \sim \mathrm{t}{ }^{\circ} \mathrm{C}$ are defined respectively as

$$
\begin{aligned}
& \left.c_{p}\right|_{0} ^{t}=\frac{\int_{0}^{t} c_{p} d t}{t} . \\
& \left.c_{v}\right|_{0} ^{t}=\frac{\int_{0}^{t} c_{v} d t}{t} .
\end{aligned}
$$

The enthalpy difference and thermodynamic energy difference can be written as

$$
\begin{aligned}
& \Delta h=\left.t_{2} \cdot c_{p}\right|_{0} ^{t_{2}}-\left.t_{1} \cdot c_{p}\right|_{0} ^{t_{1}} . \\
& \Delta u=\left.t_{2} \cdot c_{v}\right|_{0} ^{t_{2}}-\left.t_{1} \cdot c_{v}\right|_{0} ^{t_{1}} .
\end{aligned}
$$

Thus the integral operation in Eq. (1) or Eq. (2) is converted to a simple arithmetic operation and the accuracy of integral calculation is still remained. This method has been widely employed in thermal engineering. Traditionally, based upon accurate data of specific heat capacity at different temperatures, values of mean specific heat capacity of gases are calculated on the interval from $0{ }^{\circ} \mathrm{C}$ to arbitrary temperature $t$ and listed in the tables for use $[1,8]$.

To keep the table spaces compact, the temperature interval in the table of mean specific heat capacity is wide. Interpolation calculation is usually required to determine the mean specific heat capacity on the region from 0 to temperature $t\left({ }^{\circ} \mathrm{C}\right)$ and inconvenience is obvious. It is necessary and useful to correlate the tabular data of mean specific heat capacity with temperature to obtain a simple equation to further simplify the calculation for enthalpy difference in engineering applications.

\section{Correlation of mean specific heat capacity data to temperature}

The equation used for correlating the mean specific heat capacity data with temperature should be simple in form and has reasonable accuracy for calculation. Thus obtained equation is accordance with 
the purpose of introducing the concept of mean specific heat capacity $[9,10]$. By calculation we realize that if we use a polynomial to fit all data in the whole range of $0-1200{ }^{\circ} \mathrm{C}$, only a cubic or higher polynomial can give good accuracy of fitting. But a cubic polynomial is complex and not desired. Through examining the mean specific heat capacity data in literatures $[1,8]$ we divided the whole temperature range into several subintervals and on each subinterval chose a linear function of temperature, Eq. (11) to fit the data of mean specific heat capacity with least square method.

$$
\left.c_{p}\right|_{0} ^{t}=a+b \cdot t
$$

A simple formula to correlate mean isobaric specific heat capacity with temperature is thus obtained. In this way the accuracy and simplicity of calculation of enthalpy difference can be kept. It is meaningless to adopt a more complex function to improve fitting accuracy. If the formula is complex in form, the direct integral calculation of Eq. (1) and Eq. (2) would be more proper.

For the data of mean specific heat capacity of seven common gases in the literature $[1,8]$, the regressed coefficients and deviations of Eq.(11) are shown in Table 1.

Table 1 Coefficients of Equation (11)

\begin{tabular}{|c|c|c|c|c|c|c|}
\hline No. & gas & $a$ & $b$ & $\delta_{\max }[\%]$ & $\delta_{\text {ave }}[\%]$ & $\begin{array}{c}\text { Temperature } \\
{\left[{ }^{\circ} \mathrm{C}\right]}\end{array}$ \\
\hline 1 & $\mathrm{O}_{2}$ & $\begin{array}{l}0.91320 \\
0.91175 \\
0.94720\end{array}$ & $\begin{array}{l}1.1700 \times 10^{-4} \\
1.3257 \times 10^{-4} \\
8.7000 \times 10^{-5}\end{array}$ & $\begin{array}{l}0.19 \\
0.18 \\
0.08\end{array}$ & $\begin{array}{l}0.18 \\
0.11 \\
0.06\end{array}$ & $\begin{array}{c}0 \sim 300 \\
300 \sim 800 \\
800 \sim 1200\end{array}$ \\
\hline 2 & $\mathrm{~N}_{2}$ & $\begin{array}{l}1.0378 \\
1.0186 \\
1.0202\end{array}$ & $\begin{array}{l}3.3000 \times 10^{-5} \\
9.7143 \times 10^{-5} \\
9.7000 \times 10^{-5}\end{array}$ & $\begin{array}{l}0.14 \\
0.13 \\
0.08\end{array}$ & $\begin{array}{l}0.13 \\
0.08 \\
0.06\end{array}$ & $\begin{array}{c}0 \sim 300 \\
300 \sim 800 \\
800 \sim 1200\end{array}$ \\
\hline 3 & $\mathrm{CO}$ & $\begin{array}{l}1.0386 \\
1.0194 \\
1.0296\end{array}$ & $\begin{array}{l}4.6000 \times 10^{-5} \\
1.1171 \times 10^{-4} \\
1.0000 \times 10^{-4}\end{array}$ & $\begin{array}{l}0.18 \\
0.11 \\
0.06\end{array}$ & $\begin{array}{l}0.15 \\
0.06 \\
0.05\end{array}$ & $\begin{array}{c}0 \sim 300 \\
300 \sim 800 \\
800 \sim 1200\end{array}$ \\
\hline 4 & $\mathrm{CO}_{2}$ & $\begin{array}{l}0.8181 \\
0.8731 \\
0.9504\end{array}$ & $\begin{array}{l}4.4600 \times 10^{-4} \\
2.7143 \times 10^{-4} \\
1.7000 \times 10^{-4}\end{array}$ & $\begin{array}{l}0.33 \\
0.55 \\
0.16\end{array}$ & $\begin{array}{l}0.30 \\
0.36 \\
0.11\end{array}$ & $\begin{array}{c}0 \sim 300 \\
300 \sim 800 \\
800 \sim 1200\end{array}$ \\
\hline 5 & $\mathrm{H}_{2} \mathrm{O}$ & $\begin{array}{l}1.8561 \\
1.8234 \\
1.8044\end{array}$ & $\begin{array}{l}2.0100 \times 10^{-4} \\
3.1229 \times 10^{-4} \\
3.3900 \times 10^{-4}\end{array}$ & $\begin{array}{l}0.32 \\
0.19 \\
0.06\end{array}$ & $\begin{array}{l}0.28 \\
0.12 \\
0.04\end{array}$ & $\begin{array}{c}0 \sim 300 \\
300 \sim 800 \\
800 \sim 1200\end{array}$ \\
\hline 6 & Air & $\begin{array}{l}1.0026 \\
0.9865 \\
0.9972\end{array}$ & $\begin{array}{l}5.1000 \times 10^{-5} \\
1.0571 \times 10^{-4} \\
9.3000 \times 10^{-5}\end{array}$ & $\begin{array}{l}0.17 \\
0.08 \\
0.08\end{array}$ & $\begin{array}{l}0.13 \\
0.04 \\
0.06\end{array}$ & $\begin{array}{c}0 \sim 300 \\
300 \sim 800 \\
800 \sim 1200\end{array}$ \\
\hline 7 & $\mathrm{SO}_{2}$ & $\begin{array}{l}0.6081 \\
0.6460 \\
0.6992\end{array}$ & $\begin{array}{l}2.6600 \times 10^{-4} \\
1.5029 \times 10^{-4} \\
8.2000 \times 10^{-5}\end{array}$ & $\begin{array}{l}0.13 \\
0.42 \\
0.28\end{array}$ & $\begin{array}{l}0.10 \\
0.28 \\
0.22\end{array}$ & $\begin{array}{c}0 \sim 300 \\
300 \sim 800 \\
800 \sim 1200\end{array}$ \\
\hline
\end{tabular}

Note: $\delta_{\mathrm{i}}=$ (cal. value - ref. value. $) /$ ref. value, $\delta_{\max }=\max \left\{\left|\delta_{\mathrm{i}}\right|, \mathrm{i}=1,2, \ldots \mathrm{N}\right\}, \delta_{\text {ave }}=\sum|\delta \mathrm{i}| / \mathrm{N}$

As can be seen from Table 1, Eq.11 is satisfactory. The average deviations of the calculated values of Eq. 11 and reference values of mean isobaric specific heat capacity are less than $0.3 \%$ for all the gases in the temperature range from 0 to $1200{ }^{\circ} \mathrm{C}$, except $\mathrm{CO}_{2}$. For $\mathrm{CO}_{2}$, only in the subinterval of $300{ }^{\circ} \mathrm{C}$ to $800{ }^{\circ} \mathrm{C}$ is the average deviation $0.36 \%$. The maximum deviations are $0.55 \%$ for $\mathrm{CO}_{2}$ in the range of $300^{\circ} \mathrm{C}$ to $800{ }^{\circ} \mathrm{C}$ and $0.42 \%$ for $\mathrm{SO}_{2}$ in the same range respectively. For other gases, the maximum deviations are all below $0.35 \%$ in the whole temperature range. Eq. 11 could offer good enough accuracy to meet the requirements of engineering calculation. This indicates that the method 
used to fit mean specific heat capacity data in this paper is correct and valid and therefore the formula obtained has high accuracy.

According to Mayer formula $c_{p}-c_{v}=R$ and the definitions of mean specific heat capacities at constant pressure and constant volume, the following formula is derived easily

$$
\left.c_{v}\right|_{0} ^{t}=\left.c_{p}\right|_{0} ^{t}-R
$$

Where $R$ is gas constant $(\mathrm{kJ} / \mathrm{kg} \cdot \mathrm{K})$. From Eq. (12) and Table 1, the formula and its coefficients of mean isochoric specific heat capacity are therefore derived with ease.

\section{Conclusion}

The method of formulation of mean specific heat capacity data in tables was discussed in this paper. A linear equation of temperature was used to fit the data of mean specific heat capacity and an empirical formula calculating the mean specific heat capacity over the range of $0-\mathrm{t}\left({ }^{\circ} \mathrm{C}\right)$ was obtained. To improve the formula accuracy, fitting should be performed piecewise over a wide range of temperature. As instances, the data of mean isobaric specific heat capacity were fitted for 7 gases over the range of $0-1200^{\circ} \mathrm{C}$ and the coefficients of the formula regressed were regressed. Calculation and analysis indicate that the method used to fit mean specific heat capacity data in this paper is correct and valid, and the formula obtained is simple in form and accurate in calculation. The application of the formula of mean specific heat capacity proposed in this paper can simplify the process of calculation on the enthalpy difference and thermodynamic energy difference of gases.

\section{References}

[1] Yan Jialu, Engineering Thermodynamics, Power Industry Press, Beijing, 2010.

[2] Kenneth Wark, Jr. and Donald E. Richards, Thermodynamics (Sixth Edition), Qinghua University Press, Beijing, 2006.

[3] Chu Zhaoxing, Ji Jianhu, Analysis and application of mine air thermal absorption capacity, Coal Science and Technology, 40(2012) 70-73

[4] Tong Yan, LI Xiaofei, The application condition of the formulas of the change of enthalpy and thermodynamics Energy, Technology of West China 11(2012) 69-71.

[5] Zheng Shili, Zhang Yi and Cui Jinlan, Thermodynamic calculation software and its application, Computers and Applied Chemistry 15 (1998)373-377.

[6] Yuan Weimin, A new formula for predicting heat capacity of ideal gases, Petroleum Engineering Construction, 39(2013) 7-10.

[7] Bruce. E. Poling, John M. Prausnitz, John P. O’Connell, The Properties of Gases and Liquids (Fifth Edition), McGraw-Hill , New Jork, 2001

[8] Bi Mingshu, Engineering Thermodynamics,Beijing,Chemical Industry Press, 2011.

[9] Yang Dongfang, Yang Yongping, Several linear fitting comparison of mean specific heat capacity at constant pressure for R717 gas phase and liquid phase, Friend of Science Ameteur, No.12(2012) 128-130.

[10] Lin Hongliang, Li Zhi, Fu Baorong, Analysis on Matlab low-temperature flue Gas enthalpy and specific heat, Ship Power Technology, 32 (2012) 26-27 